\title{
Acoustic Emission Waveform Analysis of Sandstone Failure with Different Water Content
}

\author{
Hongru Li $\mathbb{D},{ }^{1,2}$ Manchao He $\mathbb{D}^{1,2}$ Rongxi Shen, ${ }^{3}$ Yingming Xiao $\mathbb{D}^{1,2}$ and Tai Cheng $\mathbb{D}^{1,2}$ \\ ${ }^{1}$ Department of Geotechnical Engineering, College of Civil Engineering, Tongji University, Shanghai 200092, China \\ ${ }^{2}$ Key Laboratory of Geotechnical and Underground Engineering of Ministry of Education, Tongji University, Shanghai 200092, China \\ ${ }^{3}$ School of Safety Engineering, China University of Mining and Technology, Xuzhou, Jiangsu 221116, China
}

Correspondence should be addressed to Manchao He; hemanchao@263.net

Received 1 June 2021; Accepted 19 July 2021; Published 4 August 2021

Academic Editor: Tianshou Ma

Copyright () 2021 Hongru Li et al. This is an open access article distributed under the Creative Commons Attribution License, which permits unrestricted use, distribution, and reproduction in any medium, provided the original work is properly cited.

Previous studies have shown that water can reduce the acoustic emission (AE) energy and other parameters during rock failure. However, the fracture mechanism of rock can be better reflected by analyzing the AE waveform. Therefore, this paper conducted experiments of uniaxial compression on sandstone samples of various water contents and collected AE signals simultaneously. Analyses of fast Fourier transform (FFT) and Hilbert-Huang transform (HHT) were performed on the AE waveform when the sample failed. The results show that as the water content increases, the frequency and intensity of the AE signal will decrease. The influence of water on the intensity of the AE signal is greater than that on the frequency. Through the analysis of the energy mechanism of rock failure, it is pointed out that the frequency and intensity of AE signal are closely related to elastic energy index $W_{\mathrm{ET}}$ and burst energy index $K_{\mathrm{E}}$. The research results have guiding significance for the monitoring of rockburst.

\section{Introduction}

As the depth of underground engineering increases, the surrounding rock masses suffer higher ground stress, higher temperature, high permeability pressure, and strong disturbance; rock dynamic disasters such as rockburst occur frequently $[1,2]$. Acoustic emission (AE) technology is a powerful means for monitoring rockburst disasters $[3,4]$. AE signals are elastic waves released when materials undergo plastic deformation and crack propagation under stress. AE signals contain a wealth of information about material fracture, which can reveal the fracture mechanism and damage degree of the material [5-8]. In-depth interpretation of AE signals is very important for rockburst monitoring.

At present, the analysis methods of $\mathrm{AE}$ signal during rock failure under load mainly include parameter analysis and waveform analysis [9]. The parameter analysis is a method used to make statistics of the characteristic parameters (including energy and count) of the $\mathrm{AE}$ waveform during the rock failure process, which is able to reflect the degree of rock damage [10]. Figure 1 shows the various waveform parameters of the $\mathrm{AE}$ signal. The waveform analysis method is to transform the waveform of $\mathrm{AE}$ signal from the time domain to the frequency domain and then get its frequency domain characteristics. Waveform analysis can directly reflect the rock fracture mechanism [11]. Extensive research [12-15] shows that the AE signal of rock is mainly manifested as high frequency and low amplitude under lower stress levels; at higher stress levels, low-frequency and highamplitude AE signals will appear accompanied by large-scale fractures in the rock. There is an inverse relationship between the frequency of the AE signal and the fracture size. In addition, some scholars have other opinions. Li et al. [16] believe tensile fracture generates $\mathrm{AE}$ signals of low frequency while high-frequency $\mathrm{AE}$ signals are produced by shear fracture. Zhu et al. [17] suggested that the middle-frequency AE signals may be connected with the friction of fracture surfaces.

In engineering practice, rocks are often in a groundwater environment [18]. Water will reduce strength and fracture mechanical properties (including fracture toughness and 


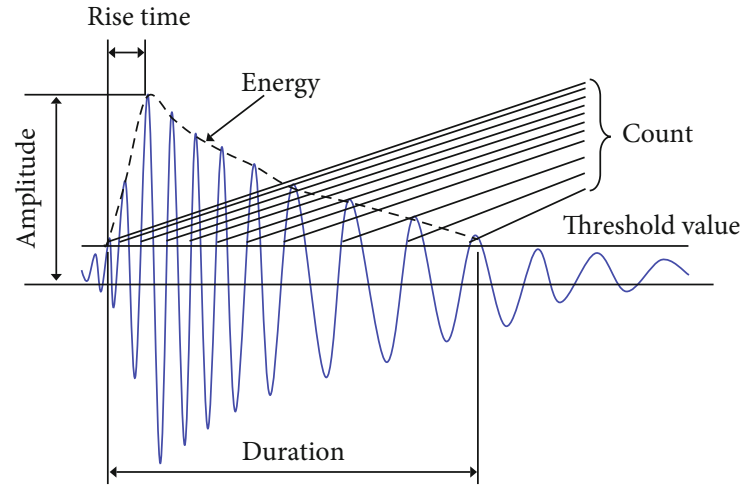

FIgURE 1: Parameters of AE waveform.

crack growth rate) of rocks and enhance their plastic characteristics, especially for rocks containing clay minerals [19-25]. Accordingly, the effects of water should be taken into full consideration when monitoring rock stability. Current researches show that water can reduce the $\mathrm{AE}$ energy, count, and other parameters in the process of rock failure [26-29]. However, there are few studies on the frequency domain characteristics of $\mathrm{AE}$ waveforms when waterbearing rocks are failure. Moreover, the relationship between the AE signal performance and the mechanical mechanism of rock failure is also worthy of further discussion.

Hilbert-Huang transform (HHT) is an advanced method transforming signals from the time domain to the frequency domain $[30,31]$. As an adaptive time-frequency localized analysis method, HHT is very suited to the analysis of nonstationary signals. Therefore, this paper prepared sandstone samples with different water contents, performed uniaxial compression tests on them, and collected AE signals. HHT analysis was performed on the $\mathrm{AE}$ waveforms when the samples failed and compared with the classical waveform analysis method (fast Fourier transform (FFT)). The frequency domain characteristics of $\mathrm{AE}$ signals when sandstone samples with different water contents failed are researched. The study findings gave guidance for improving accuracy of rockburst monitoring.

\section{Experimental Process and Results}

2.1. Sample Preparation. On the basis of the International Society of Rock Mechanics' standards, rock samples with the size of $\Phi 50 \mathrm{~mm} \times 100 \mathrm{~mm}$ were made. The used rock was white sandstone, consisted of minerals of quartz (37.6\%), muscovite (28.2\%), and kaolinite (34.1\%), and came from Renshou County, Sichuan Province, China. In order to prepare sandstone samples in various water contents, samples were soaked in water after drying. During the soaking process, the samples were weighed at regular intervals and the water content was calculated. Figure 2 shows the change of water content of a typical sample during water absorption. The samples could be saturated in about 4-5 hours. In addition, the samples were soaked in water under normal temperature and pressure.

The P-wave velocity of the samples was tested, and 12 samples with the same test results (about $2.53 \mathrm{~km} / \mathrm{s}$ ) were sorted out as the experimental samples. After drying, they

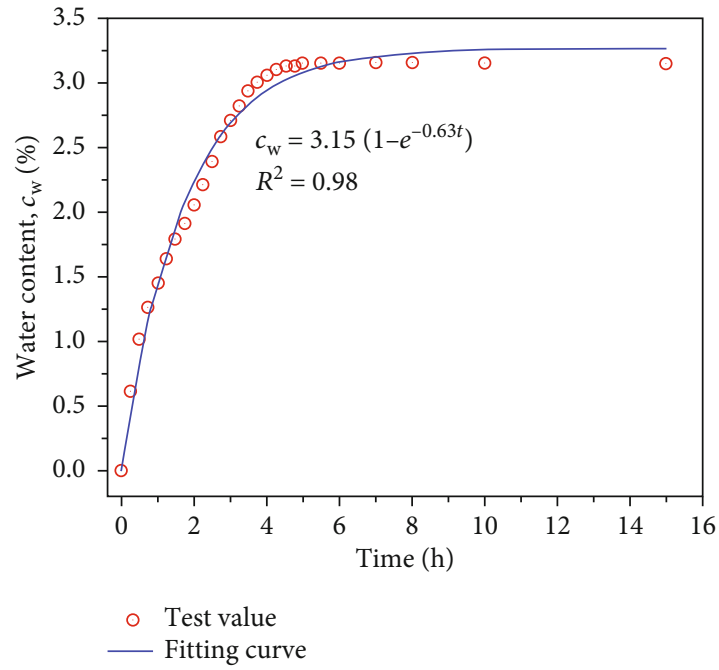

FIgURE 2: Water absorption process of sandstone.

were divided into four groups and soaked in water for different times. Table 1 shows the basic physical parameters of the sample.

2.2. Experimental System and Scheme. The experimental system primarily comprised a loading system, namely, new SANS microcomputer-controlled electrohydraulic servo pressure testing machine, and an $\mathrm{AE}$ signal acquisition system (24-channel Micro-II type AE monitoring host of American Physical Acoustics Corporation), as illustrated in Figure 3. Besides, the AE probe was NANO-30 (center frequency is $150 \mathrm{kHz}$ ). The amplification factor of $\mathrm{AE}$ signal was set as $40 \mathrm{~dB}$; the threshold value was set as $45 \mathrm{~dB}$; and the sampling rate was 2 MSPS. In order to ensure that the $\mathrm{AE}$ signal from the fracturing source was received completely, a special coupling agent was applied to the junction of the probe and the sample. AE was calibrated through the lead-breaking experiment. The follow-up experiment could only be carried out when the lead-breaking amplitude was above $95 \mathrm{~dB}$. The loading rate of the press was set to $120 \mathrm{~N} / \mathrm{s}$. The press and AE acquisition were launched synchronously until the sample was destructed.

2.3. Experimental Result. Table 1 also lists the mechanical parameters (uniaxial compressive strength, elastic modulus) of all samples, together with the cumulative total value of $\mathrm{AE}$ energy during the entire loading process. As the water content of the sample increases, its strength, elastic modulus, and total AE energy gradually decrease. This is generally consistent with previous studies. Compared with dry samples, the mean values of uniaxial compression strength, elastic model, and AE energy of saturated samples decreased $45.6 \%, 54.19 \%$, and $61.7 \%$, respectively.

Figure 4 shows the time series changes of stress, strain, and $\mathrm{AE}$ energy of a group of samples with different water contents in the course of loading. Figure 5 gives information about their stress-strain curves. Figure 6 shows the time series change of cumulative AE energy during loading. The deformation and fracture process of rock materials can be 
TABle 1: Physical parameters and experimental results of samples.

\begin{tabular}{|c|c|c|c|c|c|c|c|c|c|c|}
\hline \multirow[t]{2}{*}{ Sample no. } & \multirow[t]{2}{*}{$\begin{array}{c}\text { Density } \\
\text { (before water absorption) } \\
\left(\mathrm{g} / \mathrm{cm}^{3}\right)\end{array}$} & \multirow[t]{2}{*}{ Soaking time (h) } & \multicolumn{2}{|c|}{$\begin{array}{c}\text { Water content } \\
(\%)\end{array}$} & \multicolumn{2}{|c|}{$\begin{array}{l}\text { Uniaxial } \\
\text { compressive } \\
\text { strength } \\
(\mathrm{MPa})\end{array}$} & \multicolumn{2}{|c|}{$\begin{array}{l}\text { Elastic } \\
\text { modulus } \\
(\mathrm{GPa})\end{array}$} & \multicolumn{2}{|c|}{ Total AE energy (aJ) } \\
\hline & & & Value & Mean & Value & Mean & Value & Mean & Value & Mean \\
\hline A-1 & 2.30 & 0 & 0 & 0 & 40.70 & 42.02 & 8.68 & 8.84 & 312621 & 324275 \\
\hline A-2 & 2.31 & 0 & 0 & & 42.23 & & 8.73 & & 342312 & \\
\hline A-3 & 2.30 & 0 & 0 & & 43.12 & & 9.12 & & 317892 & \\
\hline B-1 & 2.31 & 0.50 & 1.03 & 1.03 & 35.64 & 33.48 & 6.90 & 6.54 & 212348 & 214161 \\
\hline B-2 & 2.31 & 0.50 & 1.01 & & 31.34 & & 6.44 & & 203412 & \\
\hline B-3 & 2.31 & 0.50 & 1.05 & & 33.45 & & 6.27 & & 226723 & \\
\hline $\mathrm{C}-1$ & 2.30 & 2.00 & 2.05 & 2.04 & 29.14 & 28.10 & 5.90 & 5.28 & 167364 & 158423.67 \\
\hline $\mathrm{C}-2$ & 2.30 & 2.00 & 2.04 & & 27.14 & & 5.03 & & 149214 & \\
\hline C-3 & 2.31 & 2.00 & 2.03 & & 28.03 & & 4.91 & & 158693 & \\
\hline $\mathrm{D}-1$ & 2.31 & 5.00 & 3.17 & 3.14 & 20.91 & 22.86 & 3.81 & 4.05 & 133603 & 124167.33 \\
\hline $\mathrm{D}-2$ & 2.31 & 5.00 & 3.11 & & 23.32 & & 4.13 & & 127967 & \\
\hline D-3 & 2.30 & 5.00 & 3.14 & & 24.34 & & 4.21 & & 110932 & \\
\hline
\end{tabular}

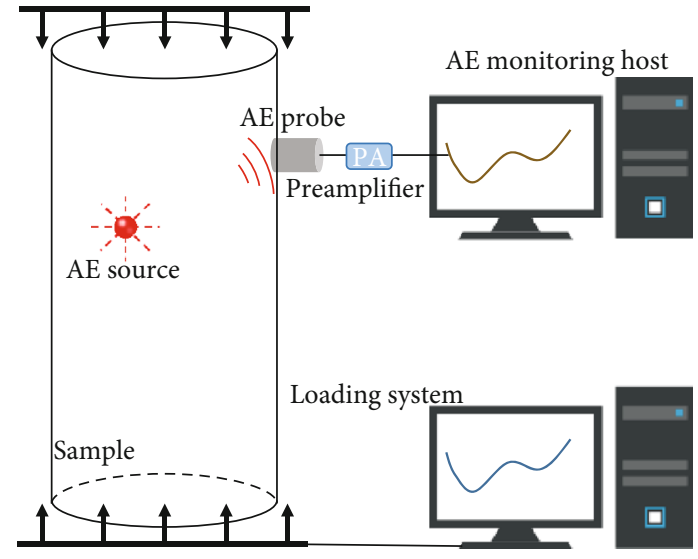

Figure 3: Experimental system schematic.

broadly classified into four phases: compaction, elastic deformation, plastic deformation, and failure. As the water content increases, the plastic deformation characteristics of the sample before the peak stress become more obvious; its strain increases significantly; and the stress-strain curve becomes more tortuous. Accompanied by stress fluctuations, the AE energy of a sample with high water content has a more obvious response in late-stage loading. When failure happens, the $\mathrm{AE}$ energy can reach the peak value. From the perspective of the entire loading process, the $\mathrm{AE}$ energy level continues to decrease with the increase of the water content. According to our previous research [9], the weakening of AE energy by water can be attributed to the change of microscopic fracture mode, the reduction of fracture mechanics properties, and the lubrication effect of water on friction.

\section{Waveform Analysis of AE}

3.1. Original Waveform and Its FFT Analysis. A group of typical waveforms of AE signal at failure time (peak stress point) of sandstone with different water contents was selected for analysis. Figure 7 shows the original waveform. When the sample is failure, its AE waveform assumes a shape that suddenly increases and then gradually decays. Comparing the $\mathrm{AE}$ waveforms of samples with different water contents, it is more obvious that the signal amplitude decreases significantly as the water content increases. And the trend of signal spikes seems to slow down. In order to reveal their frequency domain characteristics in-depth, further analysis is carried out with the help of FFT and HHT.

FFT is an efficient algorithm for discrete Fourier transform. The discrete Fourier transform $X(k)$ of sequence $x(n)$ with the length of $N$ is

$$
X(k)=\sum_{n=0}^{N-1} x(n) W_{N}^{n k}(K=0,1, \cdots, N-1)
$$

where $W_{N}=e^{-j(2 \pi / N)}$. The above formula is the basic principle of FFT. Figure 8 shows the FFT spectrums of the AE signals of samples in diverse water content. When the sample is failure, the frequency of the $\mathrm{AE}$ signal is basically distributed below $100 \mathrm{kHz}$. The main frequency (the frequency at the highest amplitude point) is lower than $30 \mathrm{kHz}$. They are low-frequency signals. The main frequency and its amplitude of all samples were counted, as shown in Figure 9. As the water content increases, the main frequency and its amplitude of the AE signal gradually decrease. But the decrease in the amplitude of the main frequency is more significant. The average amplitude of the main frequency is about $0.12 \mathrm{mV}$ for dry samples, while that of the saturated samples is $0.03 \mathrm{mV}$. The decline was more than $73 \%$. However, the main frequency is only reduced from about $25 \mathrm{kHz}$ to about $20 \mathrm{kHz}$. Therefore, the influence of water on the amplitude of AE signal is far greater than that on the frequency. 


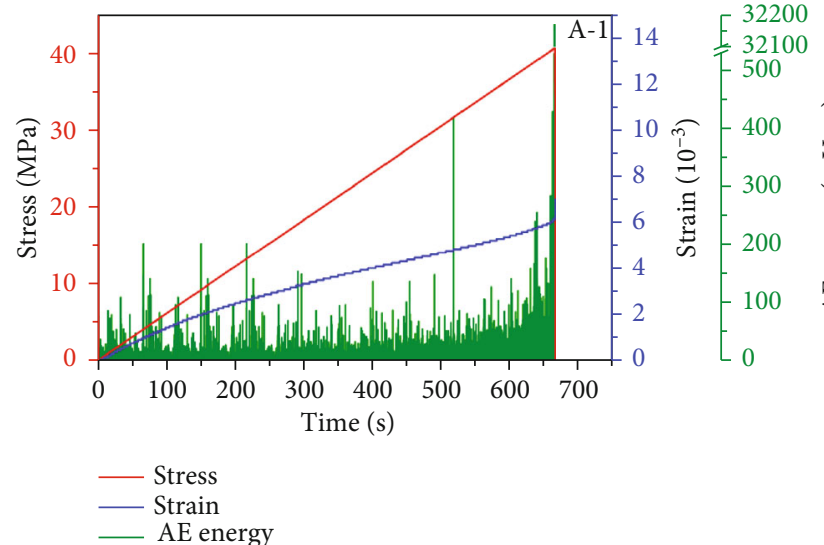

(a)

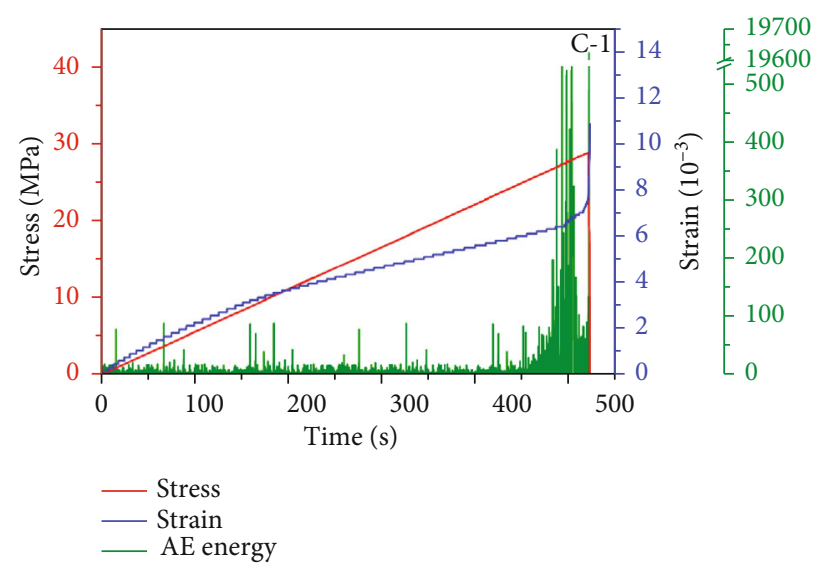

(c)

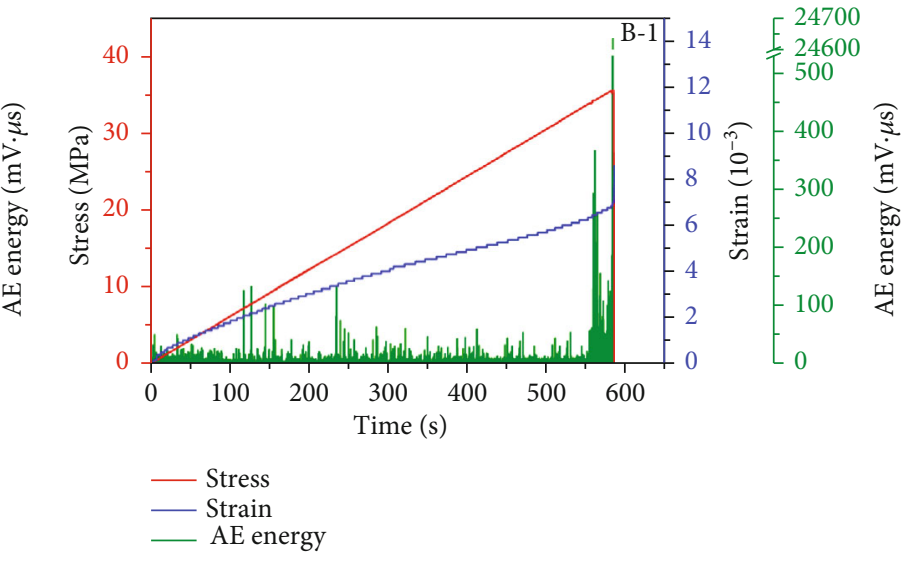

(b)

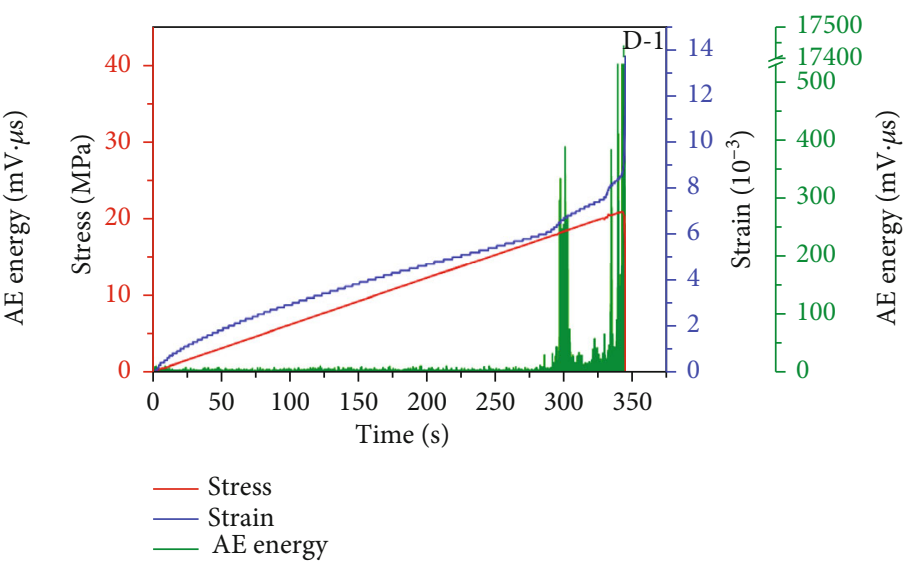

(d)

FIGURE 4: Time series changes of stress, strain, and AE energy.

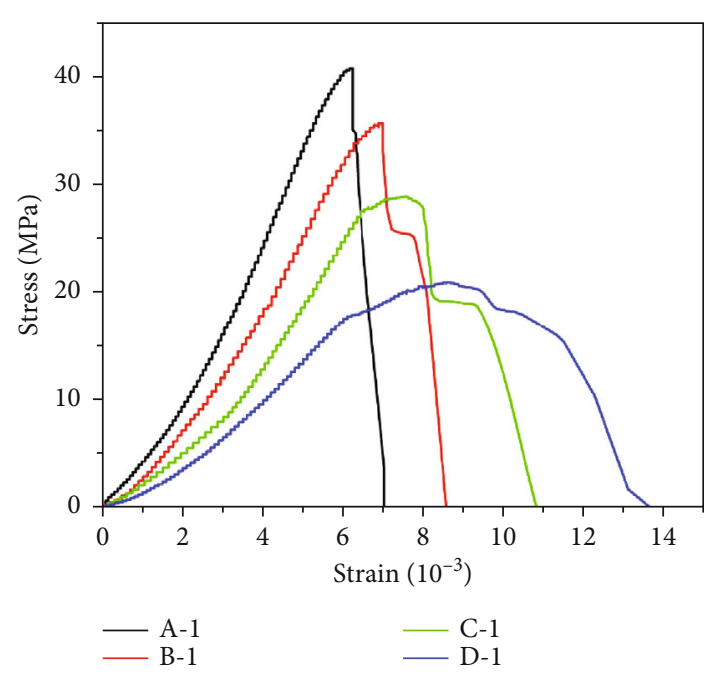

FIGURE 5: Stress-strain curve.

\subsection{HHT Analysis}

3.2.1. HHT Theory. HHT is constituted by Empirical Mode Decomposition (EMD) and Hilbert transform (HT) [30, 31]. In the first place, the complex signal is decomposed into

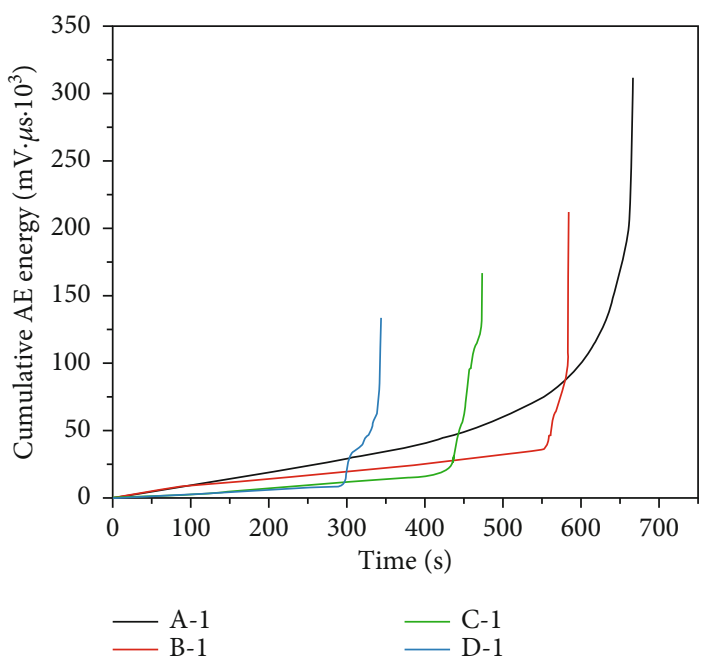

Figure 6: Time series change of cumulative AE energy.

a finite number of intrinsic mode functions (IMFs) through way of EMD, and Hilbert transform is then performed on the IMF components after decomposition so that the energy distribution spectrum (Hilbert spectrum) is obtained on the time-frequency plane. A brief description of the algorithm is as follows. 


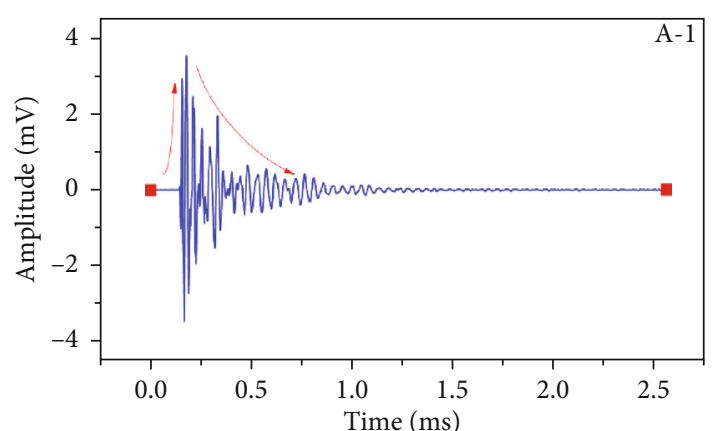

(a)

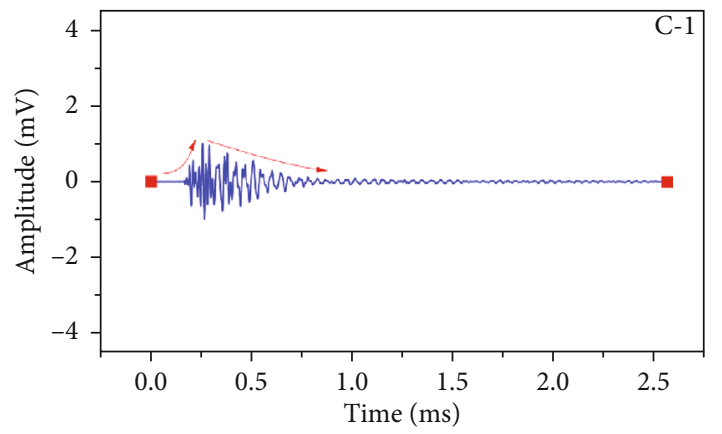

(c)

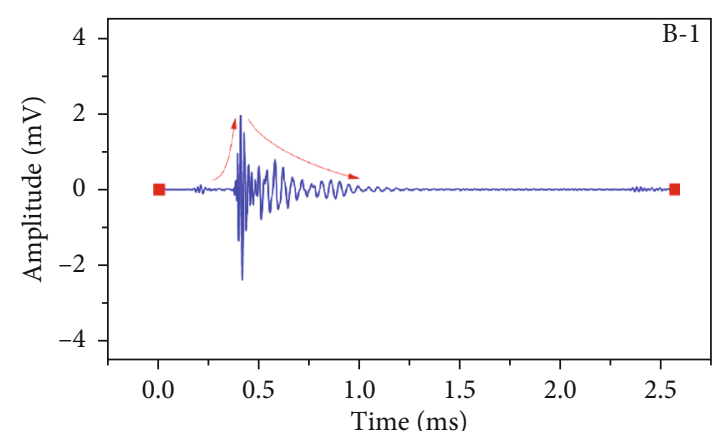

(b)

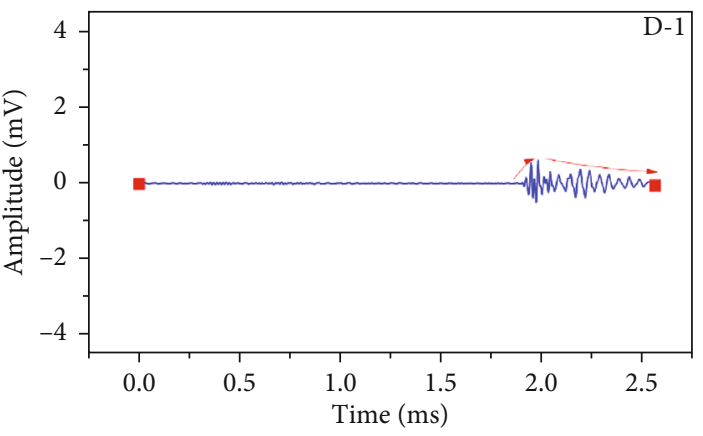

(d)

FIgURE 7: The original waveform when the samples failed.

Huang et al. [30] put forward a method of signal decomposition (EMD method) based on IMF. First, find the average value $m(t)$ of the upper envelope $v_{1}(t)$ and lower envelope $v_{2}(t)$ according to the maximum and minimum points of the signal $x(t)$, and then, calculate the difference $h_{1} t$ between $x(t)$ and $m(t)$ :

$$
x(t)-m(t)=h_{1} t
$$

Take $h_{1} t$ as a new $x(t)$, and then, repeat the above operation before $h_{1} k(t)$ obtained by $k$ cycles meets the standard defined by Huang, and the first level of decomposition comes to an end. $c_{1}=h_{1} k(t)$ is defined, and $c_{1}$ is the first intrinsic mode function $\left(\mathrm{IMF}_{\mathrm{cl}}\right)$. The rest of the part $x(t)$ $-c_{1}=r$ is subjected to the identical decomposition procedure to obtain $\mathrm{IMF}_{\mathrm{c} 2}, \mathrm{IMF}_{\mathrm{c} 3} \ldots$. It can stop until $r(t)$ is monotonous or $|r(t)|$ is tiny. So far, $n$-th order IMF components and residual $r_{n}(t)$ can represent the original signal $x(t)$

$$
x(t)=\sum_{i=1}^{n} c_{j}(t)+r_{n}(t)
$$

where $r_{n}(t)$ is the residual term, representing the average tendency of the signal; IMF components $\left(c_{1}, c_{2}, \cdots, c_{n}\right)$ contain the signal components from high to low in different frequency bands.

Perform Hilbert transform on all IMF components obtained by EMD. Combining the calculation results of all IMF components can gain the "time-frequency-energy" three-dimensional spectrum of the signal, which is called the Hilbert spectrum. The Hilbert transform on the IMF component represented by $c(t)$ is as follows:

$$
H[c(t)]=\frac{1}{\pi} P \int_{-\infty}^{+\infty} \frac{c\left(t^{\prime}\right)}{t-t^{\prime}} d t^{\prime},
$$

where $P$ is the Cauchy principal value. Then, the analytic signal of $c(t)$ is

$$
z(t)=c(t)+i H[c(t)]=\alpha(t) e^{i \theta(t)},
$$

where the amplitude function is $\alpha(t)=\sqrt{c^{2}(t)+H^{2}[c(t)]}$ and the phase function is $\theta(t)=\tan ^{-1}((H[c(t)]) /(c(t)))$. Then, the signal's instantaneous frequency is

$$
f(t)=\frac{d \theta(t)}{d t} .
$$

Neglecting the residual $r_{n}(t)$, the Hilbert spectrum of the original signal is

$$
H(f, t)=\operatorname{Re} \sum_{i=1}^{n} \alpha_{i}(t) e^{j \int \theta_{i} d t},
$$

where Re is the real part.

3.2.2. Hilbert Spectrum Analysis. Figure 10 reveals the Hilbert spectrum of the AE signal when samples with different water contents failed. The color bar on the left in the figure indicates the energy level. Compared with the FFT spectrum, the Hilbert spectrum can clearly show the instantaneous 


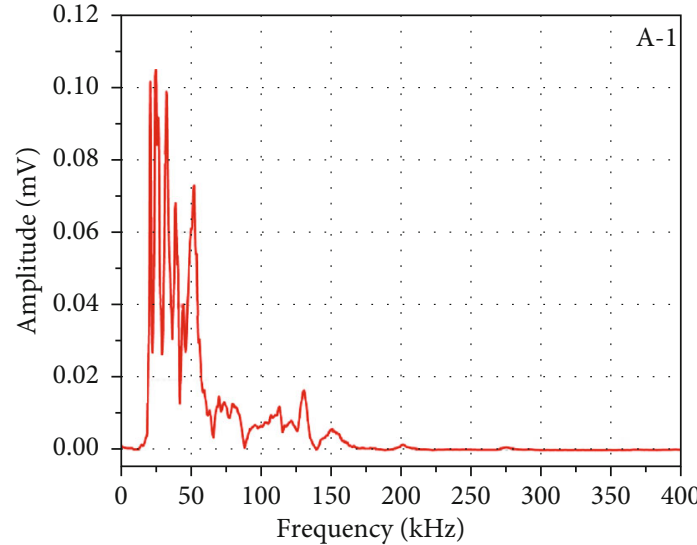

(a)

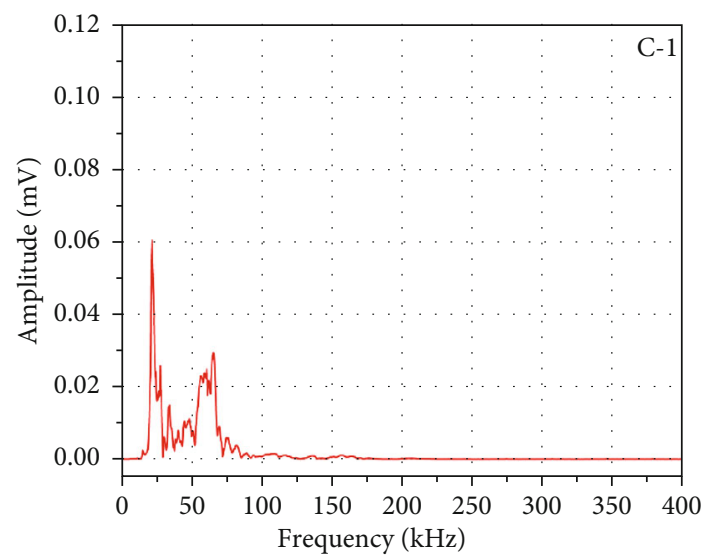

(c)

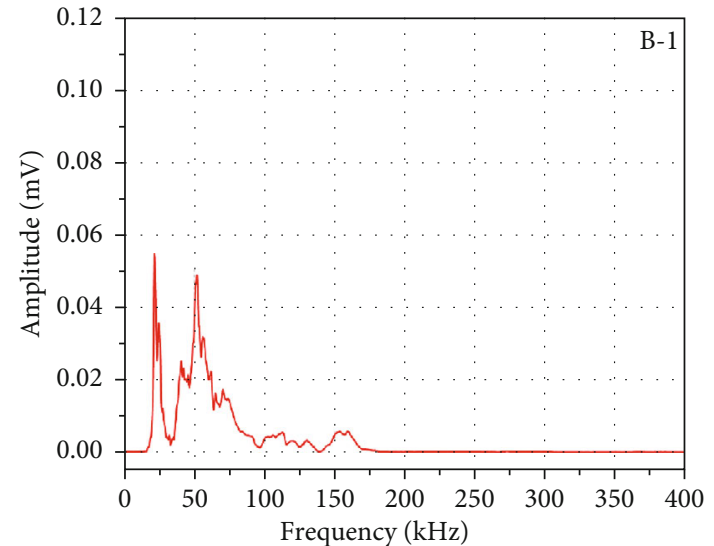

(b)

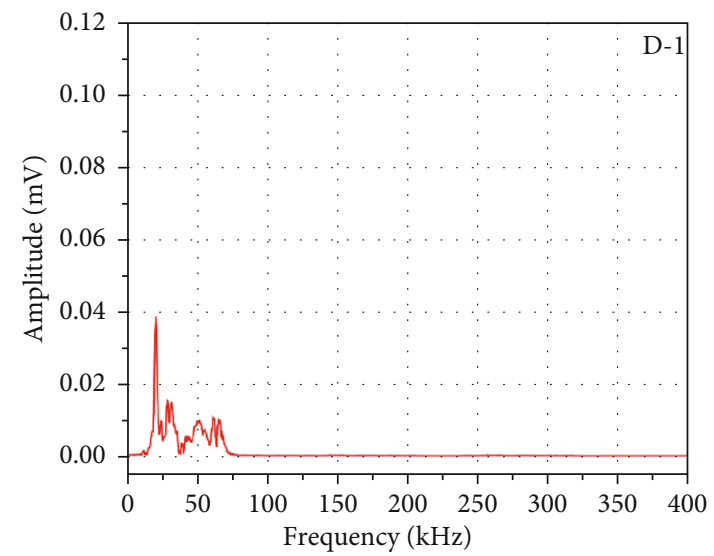

(d)

FIGURE 8: FFT spectrums of samples with different water contents.

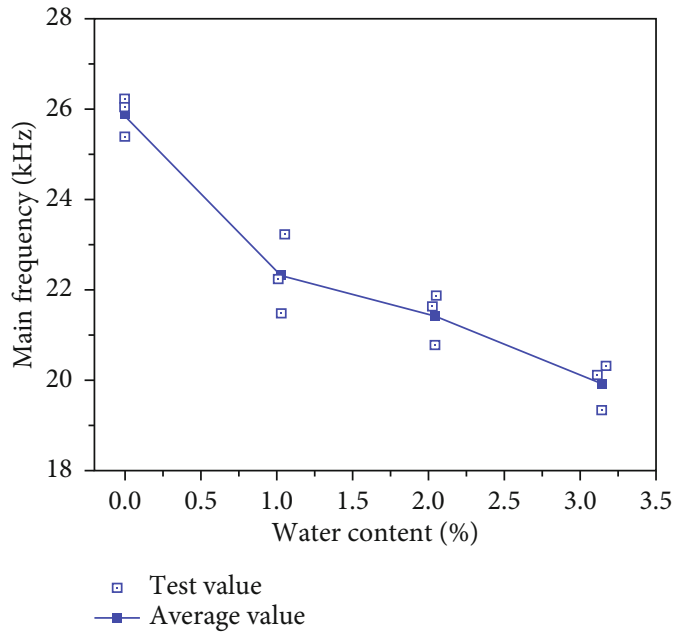

(a)

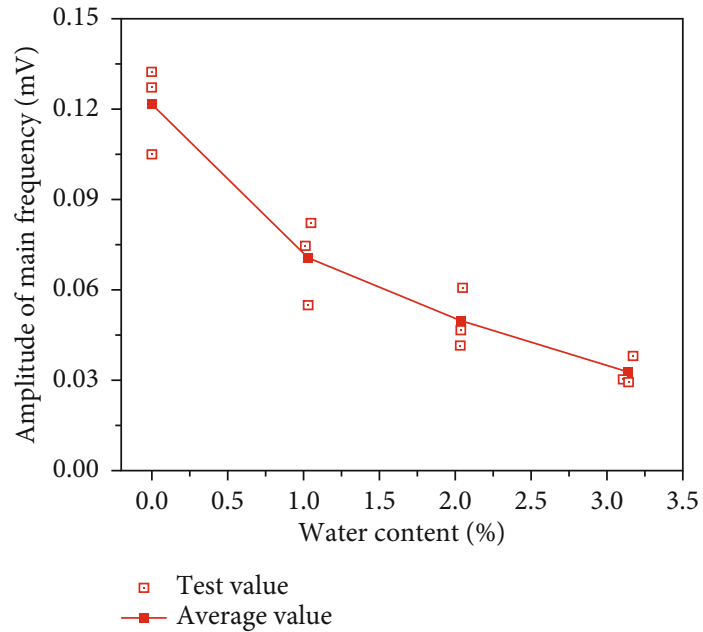

(b)

FIGURE 9: Main frequency and main-frequency amplitude of samples with different water contents.

performance of signal frequency and energy. During the signal duration, their frequency is basically lower than $120 \mathrm{kHz}$. And signals all appear the situation that their frequency reduces as time increases. As the water content increases, the overall signal frequency level has a downward trend. The signal performance of saturated sample below $40 \mathrm{kHz}$ is better than that of samples with lower water content. The more significant difference is in energy. The maximum 


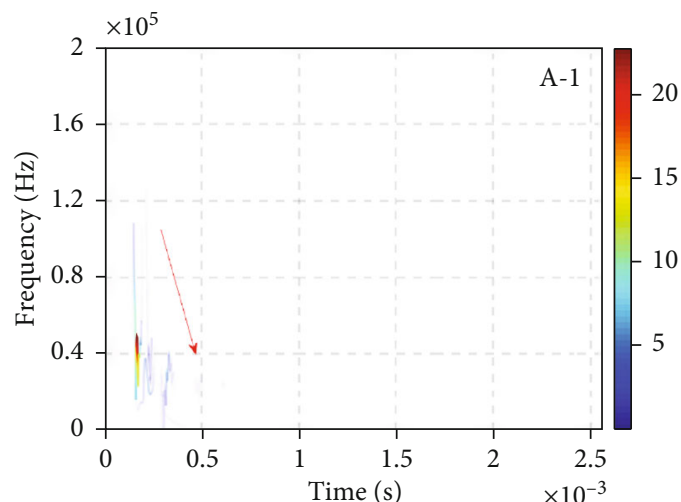

(a)

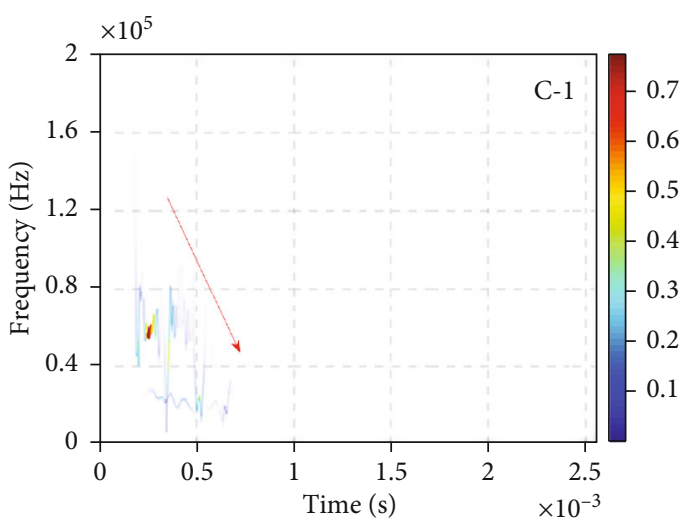

(c)

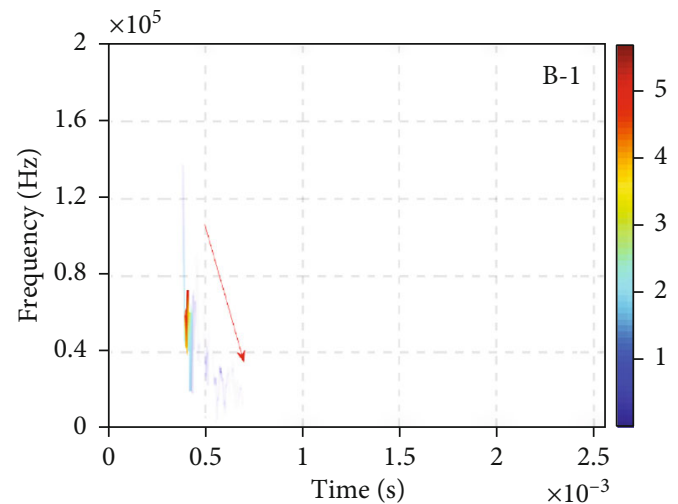

(b)

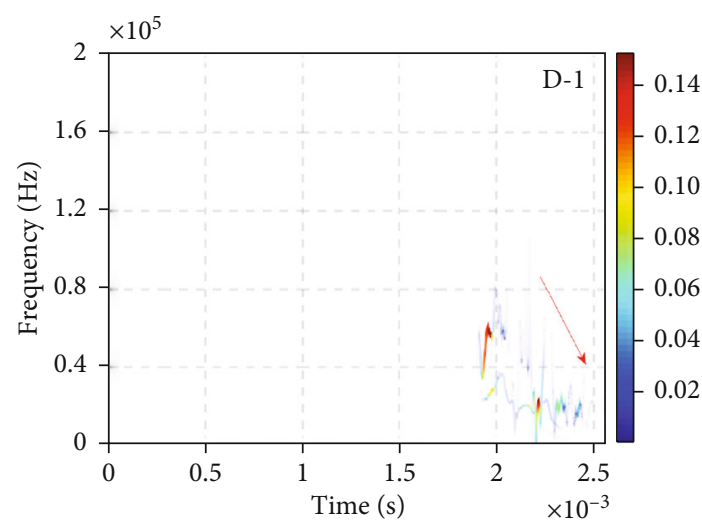

(d)

FIgURE 10: The Hilbert spectrum of samples with different water contents.

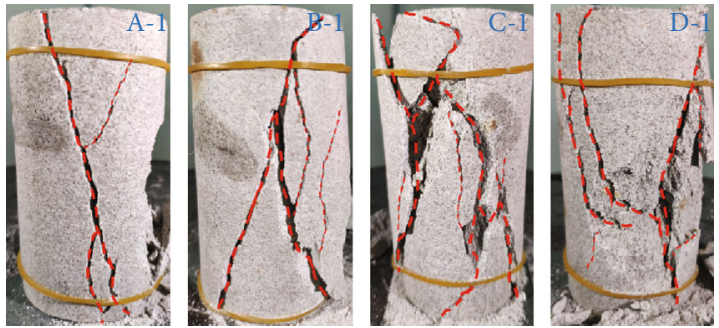

FIGURE 11: Failure modes of samples with different water contents.

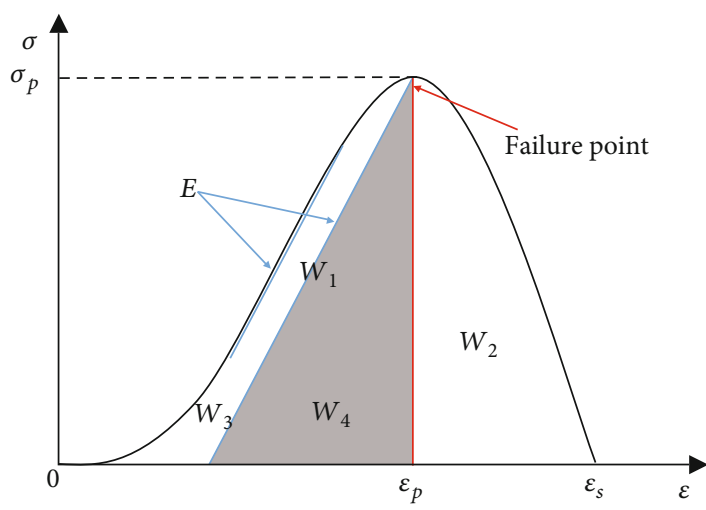

FIGURE 12: The energy evolution process of rock under uniaxial compression.

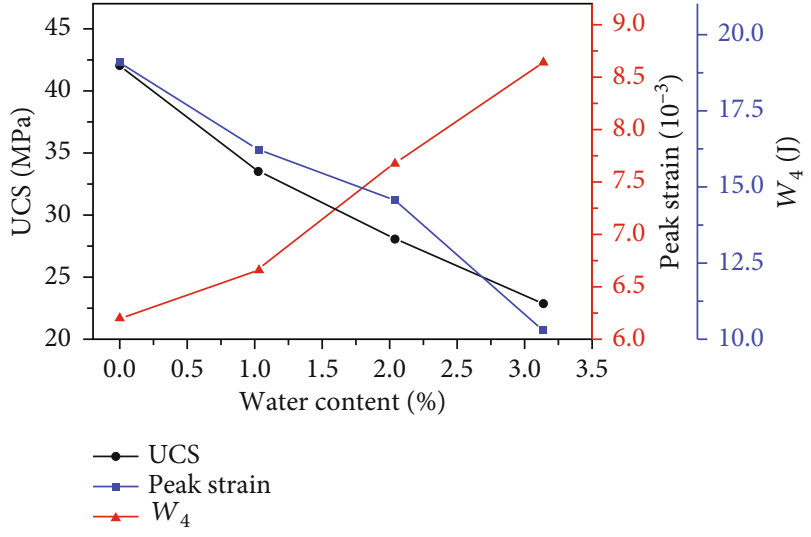

FIgURE 13: UCS, peak strain, and $W_{4}$ of samples with different water contents.

energy value of the dry sample can reach more than 20 , while that of the saturated sample is just over 0.14 .

\section{Discussion}

According to the study of Wang et al. [32], the frequency of the $\mathrm{AE}$ signal produced by crack propagation in brittle materials is related to the rate of fracture energy release. After further derivation, they believe that the frequency of the $\mathrm{AE}$ 


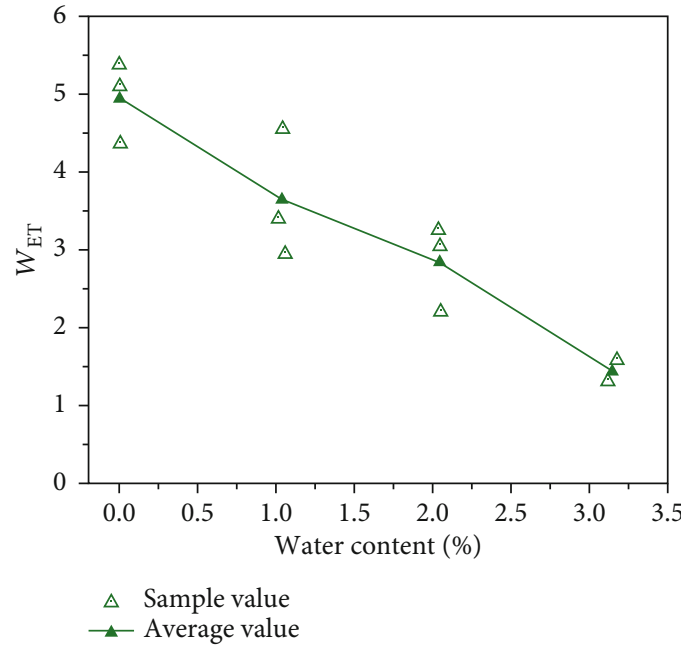

(a)

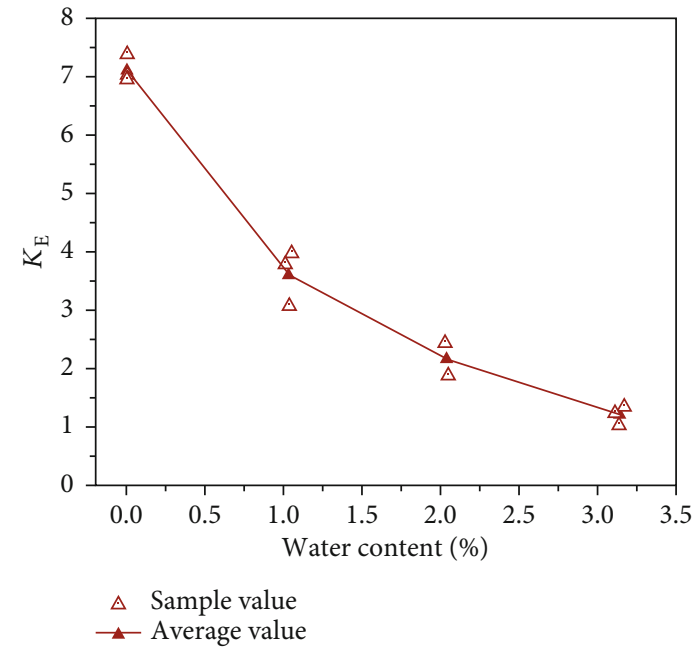

(b)

Figure 14: $W_{\mathrm{ET}}$ and $K_{\mathrm{E}}$ of samples with different water contents.

signal is positively correlated with the effective elastic modulus of the medium, that is,

$$
f \propto \bar{E} .
$$

Water will reduce the fracture toughness of the rock and its crack propagation speed, resulting in a weakening of the release of fracture energy, which in turn weakens the AE signal [24]. These can explain the results of this experiment to a certain extent. However, the failure mode of rock is often the composite failure of tension and shear, and there is friction between the fractured surfaces. This is an important reason for the complexity of AE signals. The failure mode of a group of samples with different moisture contents is shown in Figure 11. The failure of sandstone samples is mainly shear failure and mixed with tensile fracture. Due to the deterioration of water in sandstone, the number of cracks increases with the increase of water content [9]. Therefore, the single-crack propagation model cannot fully explain the decrease of frequency and intensity (amplitude or energy) of the $\mathrm{AE}$ signal caused by water when rock failed.

In fact, the failure process of rock under load is the transformation process of strain energy (including elastic energy and dissipation energy), and its failure can be regarded as a state instability driven by energy [33]. And AE is a form of energy dissipation. Figure 12 shows the energy evolution process of rock under uniaxial compression. $W_{1}$ is the prepeak total strain energy; $W_{2}$ is the postpeak dissipated energy; $W_{3}$ is the prepeak dissipated energy; $W_{4}$ is the prepeak recoverable elastic energy. As the load reaches the peak stress, the elastic energy accumulated in the rock $\left(W_{4}\right)$ reaches the limit. Coupled with the continuous work of the press $\left(W_{2}\right)$, these energies will be dissipated in various forms in a short time (such as the kinetic energy of rock block, plastic deformation energy, surface energy of new cracks, work to overcome friction, $\mathrm{AE}$, and electromagnetic radiation) and cause rock failure and instability. The elastic energy index $\left(W_{\mathrm{ET}}\right)$ and burst energy index $\left(K_{\mathrm{E}}\right)$ were defined by scholars and used as important indicators to determine the burst potentiality of coal and rock [34], as follows:

$$
\begin{gathered}
W_{\mathrm{ET}}=\frac{W_{4}}{W_{3}}, \\
K_{\mathrm{E}}=\frac{W_{1}}{W_{2}} .
\end{gathered}
$$

Among them, $W_{1}=\int_{0}^{\varepsilon_{p}} \sigma d \varepsilon$ refers to the area before the peak of the stress-strain curve; $W_{2}=\int_{\varepsilon_{p}}^{\varepsilon_{s}} \sigma d \varepsilon$ means the area after the peak of the stress-strain curve; $W_{3}=W_{1}-W_{4}$. $W_{4}$ is the elastic energy that the rock can recover after unloading. In the analysis of uniaxial compression experiment [35], $W_{4}$ is often calculated approximately as

$$
W_{4}=\frac{\sigma_{p}^{2}}{2 E} .
$$

$E$ refers to the elastic modulus of rock.

Figure 13 shows the mean values of uniaxial compressive strength (UCS), peak strain (strain when stress reaches UCS), and $W_{4}$ for all samples. With the increase of water content, the strength of the sample decreases; and more significant plastic deformation leads to energy dissipation. These result in less elastic energy accumulation $\left(W_{4}\right)$ before the peak. The energy source of rock failure is mainly the elastic energy accumulated before the peak and the continuous work of the press after the peak. Less elastic energy accumulation $\left(W_{4}\right)$ is not enough to support complete failure of rock. Therefore, the higher the water content of the sample, the more work the press does after the peak $\left(W_{2}\right)$.

The higher the concentration of elastic energy before the peak and less work done by the press after the peak, the more violent and sudden the rock failure is. $W_{\mathrm{ET}}$ and $K_{\mathrm{E}}$ can well reflect the brittleness and burst potentiality of rocks. $W_{\mathrm{ET}}$ and $K_{\mathrm{E}}$ of all samples were calculated, 
and Figure 14 displays the results. $W_{\mathrm{ET}}$ and $K_{\mathrm{E}}$ gradually decrease with the increase of water content. This shows that the lower the water content of the rock, the more violent and sudden the energy release during failure. Along with the rock failure, the AE signal responds strongly. We believe that the performance of the AE signal is closely related to these two indicators, and they are positively correlated. The higher the $W_{\mathrm{ET}}$ and $K_{\mathrm{E}}$ of rock, the higher the frequency and intensity of AE signal.

\section{Conclusion}

According to this paper, sandstone samples of different water contents were employed to carry out experiments of uniaxial compression and collect AE signals. HHT analysis was performed on the AE waveforms when the samples failed and compared with the classical FFT. The relationship between energy mechanism of water-bearing rock failure and AE signal performance was discussed. The major conclusions are listed as follows:

(1) When the sample fails, the waveform of AE signal assumes a shape that suddenly increases and then gradually attenuates. As the water content grows, the signal amplitude falls by degrees, and the trend of signal spikes slows down

(2) The results of FFT show that AE signals are all lowfrequency signals $(<30 \mathrm{kHz})$ when samples fail. As the water content rises, the main frequency of the signal reduces slightly, while the amplitude of the main frequency decreases greatly

(3) The HHT results show that the AE signal frequency of sample failure gradually decreased with the increase of time. And the HHT results have some similar characteristics compared with the FFT. When the sample with higher water content is failure, the AE signal performs better in the lower frequency range, and its energy value is greatly reduced

(4) Through the analysis of the energy mechanism of water-bearing rock failure, it is pointed out that water will weaken the brittleness and burst potentiality of the rock and make the elastic energy index $\left(W_{\mathrm{ET}}\right)$ and burst energy index $\left(K_{\mathrm{E}}\right)$ decrease. And the frequency and intensity (amplitude or energy) characteristics of the AE signal when the rock is failure are positively correlated with $W_{\mathrm{ET}}$ and $K_{\mathrm{E}}$

\section{Data Availability}

The data used to support the findings of this study are included within the article.

\section{Conflicts of Interest}

The authors declare that they have no conflict of interest.

\section{Acknowledgments}

This research is supported by the National Natural Science Foundation of China (52074276) and Key Technology Research on Water Diversion Project for Central Area of Yunnan Province.

\section{References}

[1] J. Z. Hu, Y. J. Wang, Z. M. Ma, X. G. Ma, X. Y. Zhang, and G. Y. $\mathrm{Yu}$, "Experimental and numerical analysis of rock burst tendency and crack development characteristics of Tianhu granite," Geofluids, vol. 2021, Article ID 6681261, 12 pages, 2021.

[2] P. Konicek and J. Schreiber, "Heavy rockbursts due to longwall mining near protective pillars: a case study," International Journal of Mining Science and Technology, vol. 28, no. 5, pp. 799-805, 2018.

[3] L. J. Dong, W. Zou, X. B. Li, W. W. Shu, and Z. W. Wang, "Collaborative localization method using analytical and iterative solutions for microseismic/acoustic emission sources in the rockmass structure for underground mining," Engineering Fracture Mechanics, vol. 210, pp. 95-112, 2019.

[4] C. P. Lu, G. J. Liu, Y. Liu, N. Zhang, J. H. Xue, and L. Zhang, "Microseismic multi-parameter characteristics of rockburst hazard induced by hard roof fall and high stress concentration," International Journal of Rock Mechanics and Mining Sciences, vol. 76, pp. 18-32, 2015.

[5] S. S. Wu, X. H. Zhang, J. P. Li, and Z. Wang, "Investigation for influences of seepage on mechanical properties of rocks using acoustic emission technique," Geofluids, vol. 2020, Article ID 6693920, 10 pages, 2020.

[6] H. J. Meng, Y. Wang, B. Zhang, and S. H. Gao, "Investigation on the effect of dynamic frequency on fracture evolution in preflawed rock under multistage cyclic loads: insight from acoustic emission monitoring," Geofluids, vol. 2020, Article ID 8891395, 15 pages, 2020.

[7] L. Qiu, D. Song, X. He et al., "Multifractal of electromagnetic waveform and spectrum about coal rock samples subjected to uniaxial compression," Fractals, vol. 28, no. 4, article 2050061, 2020.

[8] V. A. Mansurov, "Acoustic emission from failing rock behaviour," Rock Mechanics and Rock Engineering, vol. 27, no. 3, pp. 173-182, 1994.

[9] H. R. Li, R. X. Shen, D. X. Li et al., “Acoustic emission multiparameter analysis of dry and saturated sandstone with cracks under uniaxial compression," Energies, vol. 12, no. 10, article 1959, 2019.

[10] R. V. Sagar, B. K. R. Prasad, and S. S. Kumar, “An experimental study on cracking evolution in concrete and cement mortar by the _b_ -value analysis of acoustic emission technique," Cement and Concrete Research, vol. 42, no. 8, pp. 1094-1104, 2012.

[11] Z. Q. Hou, C. H. Li, Z. Y. Song, Y. G. Xiao, C. Qiao, and Y. Wang, "Investigation on acoustic emission Kaiser effect and frequency spectrum characteristics of rock joints subjected to multilevel cyclic shear loads," Geofluids, vol. 2021, Article ID 5569525, 21 pages, 2021.

[12] B. H. Armstrong, "Acoustic emission prior to rockburst and earthquake," Bulletin of the Seismological Society of America, vol. 59, no. 3, pp. 1259-1279, 1969. 
[13] I. Maeda, "Spectral and source parameters of acoustic signals emitted by microcrack generation in a granite sample," Journal of Physics of the Earth, vol. 29, no. 3, pp. 241-253, 1981.

[14] M. Ohnaka and K. Mogi, "Frequency-characteristics of acoustic-emission in rocks under uniaxial compression and its relation to the fracturing process to failure," Journal of Geophysical Research-Solid Earth, vol. 87, no. B5, pp. 3873-3884, 1982.

[15] M. C. He, J. L. Miao, and J. L. Feng, "Rock burst process of limestone and its acoustic emission characteristics under true-triaxial unloading conditions," International Journal of Rock Mechanics and Mining Sciences, vol. 47, no. 2, pp. 286298, 2010.

[16] L. R. Li, J. H. Deng, L. Zheng, and J. F. Liu, "Dominant frequency characteristics of acoustic emissions in white marble during direct tensile tests," Rock Mechanics and Rock Engineering, vol. 50, no. 5, pp. 1337-1346, 2017.

[17] Z. F. Zhu, G. Q. Chen, H. Y. Xiao, H. Liu, and C. Zhao, "Study on crack propagation of rock bridge based on multi parameters analysis of acoustic emission," Chinese Journal of Rock Mechanics and Engineering, vol. 37, no. 4, pp. 909-918, 2018.

[18] K. E. Eang, T. Igarashi, M. Kondo, T. Nakatani, C. B. Tabelin, and R. Fujinaga, "Groundwater monitoring of an open-pit limestone quarry: water-rock interaction and mixing estimation within the rock layers by geochemical and statistical analyses," International Journal of Mining Science and Technology, vol. 28, no. 6, pp. 849-857, 2018.

[19] H. R. Li, R. X. Shen, E. Y. Wang et al., "Effect of water on the time-frequency characteristics of electromagnetic radiation during sandstone deformation and fracturing," Engineering Geology, vol. 265, article 105451, 2020.

[20] M. Talesnick and S. Shehadeh, "The effect of water content on the mechanical response of a high-porosity chalk," International Journal of Rock Mechanics and Mining Sciences, vol. 44, no. 4, pp. 584-600, 2007.

[21] Z. A. Erguler and R. Ulusay, "Water-induced variations in mechanical properties of clay-bearing rocks," International Journal of Rock Mechanics and Mining Sciences, vol. 46, no. 2, pp. 355-370, 2009.

[22] F. L. Pellet, M. Keshavarz, and M. Boulon, "Influence of humidity conditions on shear strength of clay rock discontinuities," Engineering Geology, vol. 157, pp. 33-38, 2013.

[23] Z. Z. Zhang and F. Gao, "Experimental investigation on the energy evolution of dry and water-saturated red sandstones," International Journal of Mining Science and Technology, vol. 25, no. 3, pp. 383-388, 2015.

[24] Z. L. Zhou, X. Cai, D. Ma, W. Z. Cao, L. Chen, and J. Zhou, "Effects of water content on fracture and mechanical behavior of sandstone with a low clay mineral content," Engineering Fracture Mechanics, vol. 193, pp. 47-65, 2018.

[25] L. X. Liang, Y. Ding, X. J. Liu, and P. Y. Luo, "Evaluation and mechanical influence of clay shale hydration using acoustic time-frequency domain characteristics," Journal of Geophysics and Engineering, vol. 16, no. 3, pp. 493-508, 2019.

[26] P. G. Ranjith, D. Jasinge, J. Y. Song, and S. K. Choi, “A study of the effect of displacement rate and moisture content on the mechanical properties of concrete: use of acoustic emission," Mechanics of Materials, vol. 40, no. 6, pp. 453-469, 2008.

[27] Q. B. Lin, P. Cao, R. H. Cao, and X. Fan, “Acoustic emission characteristics during rock fragmentation processes induced by disc cutter under different water content conditions," Applied Sciences-basel, vol. 9, no. 1, article 194, 2019.

[28] J. Guo, G. R. Feng, T. Y. Qi et al., "Dynamic mechanical behavior of dry and water saturated igneous rock with acoustic emission monitoring," Shock and Vibration, vol. 2018, Article ID 2348394, 14 pages, 2018.

[29] X. J. Liu, Y. Ding, P. G. Ranjith, and P. Luo, "Hydration index and hydrated constitutive model of clay shale using acoustic frequency spectrum," Energy Science \& Engineering, vol. 7, no. 5, pp. 1748-1766, 2019.

[30] N. E. Huang, Z. Shen, S. R. Long et al., "The empirical mode decomposition and the Hilbert spectrum for nonlinear and non-stationary time series analysis," Proceedings of the Royal Society A-Mathematical Physical Engineering Sciences, vol. 454, no. 1971, pp. 903-995, 1998.

[31] J. Zhang, W. H. Peng, F. Y. Liu, H. X. Zhang, and Z. J. Li, "Monitoring rock failure processes using the Hilbert-Huang transform of acoustic emission signals," Rock Mechanics and Rock Engineering, vol. 49, no. 2, pp. 427-442, 2016.

[32] Z. L. Wang, J. G. Ning, and H. L. Ren, "Frequency characteristics of the released stress wave by propagating cracks in brittle materials," Theoretical and Applied Fracture Mechanics, vol. 96, pp. 72-82, 2018.

[33] H. P. Xie, Y. Ju, and L. Y. Li, "Criteria for strength and structural failure of rocks based on energy dissipation and energy release principles," Chinese Journal of Rock Mechanics and Engineering, vol. 24, no. 17, pp. 3003-3010, 2005.

[34] C. D. Su, X. X. Zhai, X. Z. Wei, and B. F. Li, "Influence of saturation period on bursting liability indices for coal seam \#2 in QianQiu coal mine," Chinese Journal of Rock Mechanics and Engineering, vol. 33, no. 2, pp. 235-242, 2014.

[35] W. L. Liu, E. C. Yan, H. Dai, Y. Du, W. B. Xiao, and S. Zhao, "Study on characteristic strength and energy evolution law of Badong formation mudstone under water effect," Chinese Journal of Rock Mechanics and Engineering, vol. 39, no. 2, pp. 311-326, 2020. 